\title{
Quantitative Trait Loci and Resistance Gene Analogs Associated with Maize White Spot Resistance
}

Ubiraci Gomes de Paula Lana, Isabel Regina Prazeres de Souza, Roberto Willians Noda, Maria Marta Pastina, Jurandir Vieira Magalhaes, and Claudia Teixeira Guimaraes, Embrapa Milho e Sorgo, Sete Lagoas, MG 35701-970, Brazil

\begin{abstract}
Maize white spot (MWS), caused by the bacterium Pantoea ananatis, is one of the most important maize foliar diseases in tropical and subtropical regions, causing significant yield losses. Despite its economic importance, genetic studies of MWS are scarce. The aim of this study was to map quantitative trait loci (QTL) associated with MWS resistance and to identify resistance gene analogs (RGA) underlying these QTL. QTL mapping was performed in a tropical maize $\mathrm{F}_{2: 3}$ population, which was genotyped with simple-sequence repeat and RGA-tagged markers and phenotyped for the response to MWS in two Brazilian southeastern locations. Nine QTL explained approximately $70 \%$ of the phenotypic

variance for MWS resistance at each location, with two of them consistently detected in both environments. Data mining using 112 resistance genes cloned from different plant species revealed 1,697 RGA distributed in clusters within the maize genome. The RGA Pto19, Pto20, Pto99, and Xa26.151.4 were genetically mapped within MWS resistance QTL on chromosomes 4 and 8 and were preferentially expressed in the resistant parental line at locations where their respective QTL occurred. The consistency of QTL mapping, in silico prediction, and gene expression analyses revealed RGA and genomic regions suitable for marker-assisted selection to improve MWS resistance.
\end{abstract}

Maize white spot (MWS) is one of the most important maize foliar diseases in tropical and subtropical areas (Paccola-Meirelles et al. 2001). This disease was previously named Phaeosphaeria leaf spot (Carson 2001; Carson et al. 2005; Lopes et al. 2007; Moreira et al. 2009; Schuelter et al. 2003) due to the causal agent that was initially considered to be Phaeosphaeria maydis, a filamentous fungus detected in late leaf lesions (Fantin 1994). However, further studies isolated Pantoea ananatis, a gram-negative bacterium, from the initial stages of leaf lesions, which was then confirmed to be the causal agent of MWS (Alippi and López 2010; Bomfeti et al. 2008; Lana et al. 2012; Pérez-y-Terrón et al. 2009). Under favorable environmental conditions, MWS causes leaf senescence, shortening of the plant cycle, and a severe reduction in grain size and weight, resulting in maize yield losses of up to $63 \%$ in susceptible cultivars, especially in Brazil (Pinto et al. 1997).

Resistance to MWS is a quantitative trait and the development of resistant cultivars is the most effective and low-cost strategy to control this disease (Carson 2001; Schuelter et al. 2003). Traditionally, selection for MWS resistance has been performed under field conditions without artificial inoculation, restricting the evaluation to favorable locations for the disease occurrence (Carson 2001; Carson et al. 2005; Lopes et al. 2007; Moreira et al. 2009; Schuelter et al. 2003). Therefore, molecular markers associated with resistance genes or quantitative trait loci (QTL) are important tools to overcome this limitation (Ingvardsen et al. 2008). Despite the importance of MWS resistance for maize cropping systems, one QTL mapping study was reported for this trait using temperate (Carson et al. 2005) and one using tropical (Moreira et al. 2009) maize germplasm. QTL mapping is a key strategy for dissecting complex traits and can be used as a starting point to identify the genes underlying important traits. Additionally, the knowledge of QTL effects, their interactions, and their stability over environments are highly required for a successful marker-assisted breeding program.

Corresponding author: C. T. Guimaraes; E-mail: claudia.guimaraes@embrapa.br

*The $\boldsymbol{e}$-Xtra logo stands for "electronic extra" and indicates that one supplementary figure and three supplementary tables are published online.

Accepted for publication 7 September 2016.

C 2017 The American Phytopathological Society
Plant-pathogen interaction involves the activation of molecular signals resulting in a defense response of the plant against a wide range of pathogens (Gururani et al. 2012; Jones and Dangl 2006). Plant defense signaling requires the recognition of specific pathogen effectors by molecules produced via disease resistance $(R)$ genes in the hosts (Belkhadir et al. 2004). To date, $112 R$ genes have been isolated and cloned from 26 plant species (Plant Resistance Gene Wiki; http://prgdb.crg.eu) (Sanseverino et al. 2013). Most $R$ genes encode a limited number of proteins that share conserved domains classified based on structural motifs, such as nucleotide-binding site (NBS), leucine-rich repeat (LRR), coiled-coil (CC), transmembrane (TM), serine/threonine kinase (STK), and toll-interleukin-1 receptor (TIR) (Cooley et al. 2000; Ingvardsen et al. 2008; Sanseverino et al. 2013).

Sequence similarity among $R$ genes against a wide spectrum of plant pathogens has been used to identify resistance gene analogs (RGA) (Ameline-Torregrosa et al. 2008; Chen et al. 2015; Perazzolli et al. 2014; Sekhwal et al. 2015). RGA are widely distributed in plant genomes, often organized in clusters and sometimes strongly linked to known resistance loci (Kanazin et al. 1996; Khan et al. 2016; Meyers et al. 1999), confirming their high potential as candidate $R$ genes. The aim of this study was to map QTL associated with MWS resistance in 148 tropical maize $F_{2: 3}$ progeny and to identify RGA in these genomic regions.

\section{Materials and Methods}

Mapping population. The mapping population is derived from a cross between the inbred lines L31.2.1.2 and L726, resistant and susceptible to MWS, respectively. In all, $148 \mathrm{~F}_{2}$ individuals were genotyped with molecular markers and 100 of the $\mathrm{F}_{2: 3}$ progenies were phenotyped in the field. The parental lines and the segregating population were developed at the Brazilian Agricultural Research Corporation-Embrapa Maize and Sorghum, Sete Lagoas, Brazil.

Experimental design and plant phenotyping. Field experiments were conducted at two locations: Sete Lagoas (latitude $19^{\circ} 28^{\prime} \mathrm{S}$, longitude $44^{\circ} 15^{\prime} \mathrm{W}$, and altitude of $732 \mathrm{~m}$ ) and Uberlândia (latitude $18^{\circ} 55^{\prime} \mathrm{S}, 48^{\circ} 16^{\prime} \mathrm{W}$, and altitude of $863 \mathrm{~m}$ ) in Minas Gerais State, southeastern Brazil. One hundred $\mathrm{F}_{2: 3}$ progenies and both parents were cultivated in the 2000-01 rainy season in a randomized complete block design with three replicates. Plots were composed of $2.0-\mathrm{m}$ rows, with $0.8 \mathrm{~m}$ between the rows and 10 plants $/ \mathrm{m}$. To ensure natural occurrence of the disease, the susceptible parent was planted 
surrounding the area and randomized within the experiment in three replicates, according to the experimental design. Ten plants of each progeny were visually scored for foliar injury at the grain filling stage using a rating scale according to Schuelter et al. (2003). The grades were defined as follows: grade $1=$ no lesions; grade $2=$ scattered lesions; grade $3=$ up to $50 \%$ of the leaves presenting lesions, with severe injuries in $25 \%$ of the lower leaves; grade $4=$ up to $75 \%$ of leaves with lesions, with severe injuries in $50 \%$ of the lower leaves; and grade $5=100 \%$ of leaves with lesions, with severe injuries in $75 \%$ of the lower leaves (Fig. 1).

Analyses of variance were performed separately for each location and jointly over locations. For each location, the following statistical model was considered: $y_{i j}=\mu+b_{j}+g_{i}+\varepsilon_{i j}$, where $y_{i j}$ is the phenotype of the $i$ th individual in block $j ; \mu$ is the overall mean; $b_{j}$ is the fixed effect of block $j ; g_{i}$ is the random effect of genotype $i$, assuming that the vector $\boldsymbol{g}=\left(g_{1}, \ldots g_{\mathrm{I}}\right)$ has a normal distribution with zero mean and variance $\sigma_{g}^{2}$; and $\varepsilon_{i j}$ represents a nongenetic residual effect, in which $\boldsymbol{r}=\left(r_{11}, \ldots r_{I J}\right)$ has a normal distribution with zero mean and variance $\sigma_{e}^{2}$. Genetic $\left(\sigma_{g}^{2}\right)$ and phenotypic $\left(\sigma_{p h}^{2}\right)$ variances were estimated based on the expectation of mean squares (MS) values of the analyses of variance for each location, such as $\sigma_{\mathrm{g}}^{2}=\left(\mathrm{MS}_{\mathrm{g}}-\mathrm{MS}_{\mathrm{r}}\right) / J$ and $\sigma_{\mathrm{ph}}^{2}=$ $\mathrm{MS}_{\mathrm{g}} / J$, in which $\mathrm{MS}_{\mathrm{g}}$ and $\mathrm{MS}_{\mathrm{r}}$ are the genetic and residual MS, respectively, and $J$ is the number of replicates. Heritabilities on a progeny-mean basis were estimated for each location as $h^{2}=$ $\sigma_{g}^{2} / \sigma_{p h}^{2}$ (Bernardo 2010). Then, a joint analysis of variance over locations was performed considering the following statistical model: $y_{i j k}=\mu+l_{k}+b_{j(k)}+g_{i}+g l_{i k}+\varepsilon_{i j k}$, where $y_{i j k}$ is the phenotype of the $i$ th individual in block $j$ at location $k ; \mu$ is the overall mean; $l_{k}$ is the fixed effect of location $k ; b_{j(k)}$ is the fixed effect of block $j$ within location $k ; g_{i}$ is the random effect of genotype $i$, assuming that the vector $\boldsymbol{g}=\left(g_{1}, \ldots g_{\mathrm{I}}\right)$ has a normal distribution with zero mean and variance $\sigma_{g}^{2} ; g l_{i k}$ is the random effect of the genotype-location interaction, assuming that the vector $\boldsymbol{g}_{\mathbf{1}}=\left(g_{11}, \ldots g_{\mathrm{IK}}\right)$ has a normal distribution with zero mean and variance $\sigma_{g l}^{2}$; and $\varepsilon_{i j k}$ represents a nongenetic residual effect, in which $\boldsymbol{r}=\left(r_{111}, \ldots r_{I J K}\right)$ has a normal distribution with zero mean and variance $\sigma_{e}^{2}$. Genetic $\left(\sigma_{g}^{2}\right)$ and genotypelocation $\left(\sigma_{g l}^{2}\right)$ variances were estimated based on their respective expectation of MS values of the joint analyses of variance, such as $\sigma_{\mathrm{g}}^{2}=\left(\mathrm{MS}_{\mathrm{g}}-\mathrm{MS}_{\mathrm{gl}}\right) / J K$ and $\sigma_{\mathrm{gl}}^{2}=\left(\mathrm{MS}_{\mathrm{gl}}-\mathrm{MS}_{\mathrm{r}}\right) / J$, in which $\mathrm{MS}_{\mathrm{g}}, \mathrm{MS}_{\mathrm{gl}}$, and $\mathrm{MS}_{\mathrm{r}}$ are the genetic, genotype-location, and residual MS, respectively; and $J$ and $K$ are the number of replicates and locations, respectively. Phenotypic variance $\left(\sigma_{p h}^{2}\right)$ was estimated as $\sigma_{\mathrm{ph}}^{2}=$ $\mathrm{MS}_{\mathrm{g}} / J K$. Heritability was also estimated on a progeny-mean basis as $h^{2}=\sigma_{g}^{2} / \sigma_{p h}^{2}$. Residuals of the individual and joint analyses of variance were tested for normality based on the Shapiro-Wilk test (Shapiro and Wilk 1965), and the Box-Cox transformation (Box and Cox 1964) was applied to the response variable when necessary.

QTL mapping. Genomic DNA was extracted from the leaves of the parental lines, $F_{1}$ and $F_{2}$ individuals (Saghai-Maroof et al. 1984). The parental lines and the $F_{1}$ hybrid were genotyped with simple-sequence repeat (SSR) markers, and 209 polymorphic SSR were genotyped in the $148 \mathrm{~F}_{2}$ individuals. Polymerase chain reaction (PCR) for SSR markers was performed according to NinamangoCárdenas et al. (2003) and the amplified fragments were resolved on silver-stained $10 \%(\mathrm{wt} / \mathrm{vol})$ polyacrylamide gel electrophoresis. Primer sequences and genomic location of the SSR were obtained from the Maize Genetics and Genomics Database (MaizeGDB; http://www.maizegdb.org/data_center/locus).

The genetic map was constructed with a minimum likelihood of odds (LOD) of 3.0 and a maximum recombination frequency of 0.4 using MapMaker/EXP 3.0 (Lander et al. 1987). Map distances in centimorgans were calculated using the Kosambi mapping function (Kosambi 1943). QTL mapping was performed using multiple interval mapping (MIM) (Kao et al. 1999) implemented in QTL Cartographer version 2.5 for Windows (Wang et al. 2012). Model selection was performed using MIM, with forward selection followed by several rounds of inclusion and exclusion and adjustments of main
QTL effects and QTL interactions based on the Bayesian Information Criterion with the penalty function $c(n)=\log (n)$, in which $n=148$, according to Zeng et al. (1999). After fitting the complete model, main QTL and epistatic effects as well as the proportion of the phenotypic variance $\left(R^{2}\right)$ explained by each QTL and by the complete model were calculated. QTL intervals were established as 1 - LOD support interval (Lander and Botstein, 1989), and defined by the nearest flanking marker on each side of the interval. The absolute values of dominance by additive ratios were estimated for each QTL, which was used to characterize the gene action as follows: additive $=0.00$ to 0.20 , partial dominance $=0.21$ to 0.80 , dominance $=0.81$ to 1.20 , and overdominance $>1.20$ (Stuber et al. 1987).

Searching for maize RGA. The deduced amino acid sequences of 112 known plant disease resistance genes, available in the Plant Resistance Genes database (PRGdb 2.0; http://prgdb.crg.eu) (Sanseverino et al. 2013), were used for BLASTp searches (e-value $<\mathrm{e}^{-10}$ ) against the maize predicted proteins. These protein sequences were obtained from the latest revised version of the B73 RefGen_v3 maize genome (Zmays_284_6a.protein and Zmays_284_6a. protein_primaryTranscriptOnly.fa; http://genome.jgi.doe.gov/pages/ dynamicOrganismDownload.jsf?organism=Zmays) (Law et al. 2015). The predicted maize RGA-encoded proteins were organized according to physical location along the maize chromosomes and classified based on domains, which were surveyed using the Interproscan 5 for all applications in Blast2GO version 3 (Conesa et al. 2005). The RGA positions related to the MWS resistance QTL were predicted based on the physical position of the two closest flanking markers obtained from the MaizeGDB (http://www.maizegdb.org/data_center/locus), Gramene (http://ensembl.gramene.org/Zea_mays/Info/ Index), and Phytozome v10.3 (https://phytozome.jgi.doe.gov/pz/ portal.html) databases.

Development of RGA-tagged markers. In total, 41 maize RGA predicted in silico within the MWS resistance QTL on chromosomes 4 and 8 showing low e-value or high similarity score with $R$ genes

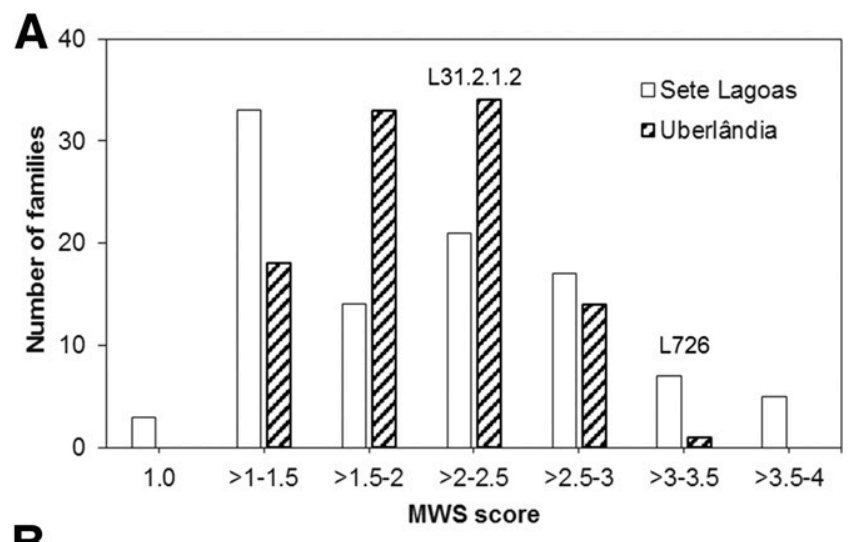

B

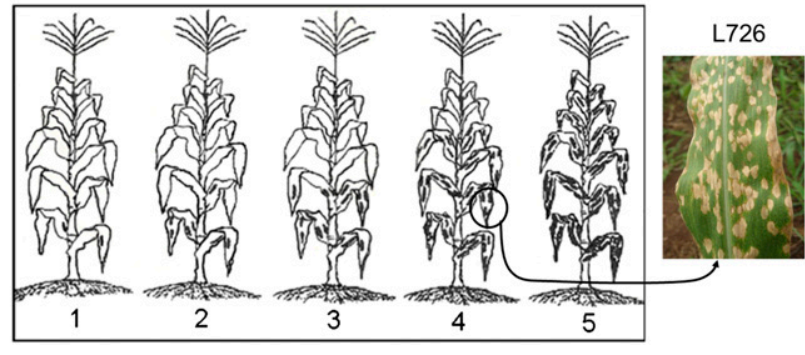

Fig. 1. Maize white spot (MWS) disease response of $F_{2: 3}$ progeny in two Brazilian locations. A, Frequency distribution of MWS disease score of $100 F_{2: 3}$ families derived from the cross L31.2.1.2 (resistant) $\times$ L726 (susceptible). Family scores are means of 10 plants evaluated in triplicate in Sete Lagoas (white column) and Uberlândia (striped column), Brazil. B, Schematic representation of the disease scale used for plant phenotyping and MWS typical symptoms in the susceptible maize parental line L726. 
were selected for further analysis. These QTL were preferentially chosen due to their consistency with previous QTL mapping studies (Carson et al. 2005; Moreira et al. 2009). Primers were designed using Primer3Plus software (http://www.bioinformatics.nl/cgi-bin/ primer3plus/primer3plus.cgi) to search for polymorphisms in the parental lines. PCR assays were performed in a total volume of $20 \mu \mathrm{l}$ containing $30 \mathrm{ng}$ of DNA, 1.5 U of Taq DNA Polymerase (Sigma Aldrich, St. Louis), $10 \mathrm{mM}$ Tris- $\mathrm{HCl}$ (pH 8.3), $50 \mathrm{mM} \mathrm{KCl,} 0.001 \%$ (wt/vol) gelatin, $0.125 \mathrm{mM}$ deoxynucleotides, and $0.4 \mu \mathrm{M}$ each primer. The amplification profile was $94^{\circ} \mathrm{C}$ for $2 \mathrm{~min}$; followed by 30 cycles of $94^{\circ} \mathrm{C}$ for $1 \mathrm{~min}, 54^{\circ} \mathrm{C}$ to $57^{\circ} \mathrm{C}$ for $1 \mathrm{~min}$ (depending on the primer melting temperature), and $72^{\circ} \mathrm{C}$ for $2 \mathrm{~min}$; and, finally, an elongation step of $72^{\circ} \mathrm{C}$ for $10 \mathrm{~min}$.

The amplification products were purified using the QIAquick Gel Extraction Kit (Qiagen, Hilden, Germany) and sequenced in both directions using the BigDye Terminator Cycle Sequencing Ready Reaction Kit (Life Technologies, Carlsbad, CA). Sequences were confirmed using BLASTN searches (Altschul et al. 1997) at the National Center for Biotechnology Information (http://www.ncbi.nlm.nih.gov). All sequences were aligned using Seqman 8.0.2(13) (DNASTAR, Madison, WI). The indels were revealed by the amplification reaction using new primers on polyacrylamide or agarose gels depending on the fragment length difference, generating markers based on sequence-tagged sites (STS). The single-nucleotide polymorphisms were converted into cleaved amplified polymorphic sequences (CAPS) markers, using an online tool to select the restriction sites (http://nc2.neb.com/NEBcutter2/). After the amplification reaction, the PCR products were digested with $5 \mathrm{U}$ of the selected restriction enzymes in a final volume of $10 \mu \mathrm{l}$. The fragments were separated on $2 \%$ (wt/vol) agarose or on $10 \%$ (wt/vol) polyacrylamide gel and visualized using ethidium bromide or silver nitrate, respectively. Polymorphic markers were genotyped in the $F_{2}$ population and mapped. The marker systems developed for each RGA, including the primers sequences, are described in Supplementary Table S1.

Expression analysis of RGA colocalized with MWS QTL. Expression analysis was performed for four candidate genes (Pto19, Pto20, Pto99, and Xa26.151.4) that genetically mapped within the confidence interval of MWS resistance QTL on chromosomes 4 and 8 . The pattern of gene expression was determined in the parental lines at 30 and 60 days after germination under field natural occurrence of MWS in Sete Lagoas and Uberlândia, Brazil. The disease symptoms could not be visually detected at 30 days after germination but the pathogen probably was already present in both fields. At 60 days after germination, which coincided with 7 to 10 days before flowering, there was a clear contrast between parents for the disease symptoms. Total RNA was isolated from $100 \mathrm{mg}$ of leaf tissue from five plants using the RNeasy Plant Mini Kit (Qiagen) and $10 \mathrm{U}$ of the DNase I RNase-free enzyme (Qiagen). cDNA synthesis was performed using $2 \mu \mathrm{g}$ of total RNA, random primers, and reverse transcription, using the High-Capacity cDNA Reverse Transcription Kit (Life Technologies) following the manufacturer's recommendations. Quantitative real-time PCR was performed on the ABI 7500 FAST

Table 1. Analyses of variance of the $F_{2: 3}$ progeny response to maize white spot disease in Sete Lagoas and Uberlândia locations, Brazil

\begin{tabular}{lrll}
\hline & & \multicolumn{2}{c}{ MS $^{\mathbf{a}}$} \\
\cline { 3 - 4 } Sources of variation & DF $^{\mathbf{b}}$ & Sete Lagoas & Uberlândia \\
\hline Blocks & 2 & $1.0685^{* *}$ & $6.5254^{* * * *}$ \\
Genotypes (G) & 99 & $1.8356^{* * *}$ & $0.6696^{* * * *}$ \\
Error & 198 & 0.1501 & 0.1369 \\
Mean & $\ldots$ & 2.03 & 2.02 \\
Coefficient of experimental variation $(\%)$ & $\ldots$ & 19.13 & 18.33 \\
Genetic variance & $\ldots$ & 0.56 & 0.18 \\
Heritability & $\ldots$ & 0.92 & 0.80 \\
\hline
\end{tabular}

${ }^{a}$ Mean square; $* *$ and $* * *$ indicate significant at $P<0.01$ and 0.001 , respectively.

${ }^{\mathrm{b}}$ Degrees of freedom. using SYBR Green Fast Kit (Life Technologies), with $\beta$-actin as the reference gene, using the primer sequences described in Supplementary Table S2. All reactions were performed in triplicate for the target and reference genes. The relative gene expression levels were calculated based on the differences in the threshold cycle $(\mathrm{Ct})$ values using the $2^{-\Delta \Delta C t}$ method (Livak and Schmittgen 2001). The gene expression of the sensitive parental line at 30 days after germination was used as the calibrator in each environment.

\section{Results}

Response of maize population and parental lines to MWS disease. The analyses of variance detected highly significant differences for the progenies in both environments individually, with low coefficient of experimental variation (19.13 and $18.33 \%)$ and high heritability estimates (0.92 and 0.80) in Sete Lagoas and Uberlândia, respectively (Table 1). The phenotypic response to MWS disease in the $\mathrm{F}_{2: 3}$ progenies exhibited a normal distribution in Uberlândia and was skewed toward resistance in Sete Lagoas, ranging from 1.0 to 4.0 (Fig. 1A). The resistant line L31.2.1.2 presented scattered lesions, whereas the susceptible line L726 showed more than $50 \%$ of the leaves with lesions, and more than $25 \%$ of lower leaves with severe injuries in both environments (Fig. 1B). In addition to the differential response of the parental lines to MWS disease, some of the segregating progenies exceeded the resistance level of the resistant parent.

However, the null hypothesis of normality was not accepted for the residuals from the single-environment analysis of variance performed in Sete Lagoas according to the Shapiro-Wilk test $(\mathrm{W}=0.9858, P$ value $=$ 0.0046; Supplementary Fig. 1A) whereas, in Uberlândia, residuals presented a normal distribution $(\mathrm{W}=0.9942, P$ value $=0.3075$; Supplementary Fig. 1B). Thus, the disease response data obtained in Sete Lagoas was transformed using the power of -0.2707 , which corresponds to the $\lambda$ estimated by the Box-Cox transformation. After transforming the data, residuals were normally distributed $(\mathrm{W}=0.9957, P$ value $=$ 0.5833; Supplementary Fig. 1C). Due to the homogeneity of residual variances, a joint analysis of variance over locations was performed and revealed significant differences for the progenies, with a significant progeny-location interaction (Table 2).

QTL mapping was performed using transformed phenotypic response to MWS in Sete Lagoas and nontransformed data in Uberlândia, separately. The data transformation inverted the signs of QTL effects. Thus, the signs of the QTL effects in Sete Lagoas were multiplied by -1 to reflect the direction of allelic effects considering the nontransformed data (Table 3). In both environments, negative QTL effects indicated that the alleles' increasing resistance was derived from the resistant line (L31.2.1.2), whereas the positive signs indicated that the susceptible parent (L726) donated the resistance alleles.

MWS resistance QTL specific and stable across environments. The linkage map was composed of 91 SSR and 8 RGA-tagged markers, covering 1,379.2 centimorgans (cM) of all 10 maize chromosomes, with a mean distance between the markers of $13.9 \mathrm{cM}$. Chromosomes 2 and 8 had the highest number of markers $(n=14)$, whereas the lowest

Table 2. Combined analysis of variance of the $\mathrm{F}_{2: 3}$ progeny response to maize white spot disease in both Sete Lagoas and Uberlândia, Brazil

\begin{tabular}{lcc}
\hline Sources of variation & DF $^{\mathbf{a}}$ & $\mathbf{M S}^{\mathbf{b}}$ \\
\hline Environments & 1 & 0.0078 \\
Genotypes & 99 & $2.1540^{* * * *}$ \\
Block/location & 4 & $3.7969^{* * *}$ \\
Genotypes $\times$ location & 99 & $0.3512^{* * *}$ \\
Error & 396 & 0.1435 \\
Mean & $\ldots$ & 2.02 \\
Coefficient of experimental variation (\%) & $\ldots$ & 18.73 \\
Genetic variance & $\ldots$ & 0.34 \\
Genotype-location interaction variance & $\ldots$ & 0.07 \\
Correlation between locations & $\ldots$ & 0.80 \\
\hline
\end{tabular}

${ }^{\text {a Degrees of freedom. }}$

${ }^{\mathrm{b}}$ Mean square; $* * *$ indicates significant at $P<0.001$. 
density was observed on chromosomes 9 and 10, with 4 markers each. The markers separated by more than $40 \mathrm{cM}$ were included and ordered based on their coordinates or physical positions according to MaizeGDB (http://www.maizegdb.org/data_center/locus). Nine QTL for MWS resistance were mapped on chromosomes $1,2,3,4$, and 8 . The QTL were named using the acronym of MWS followed by their genetic position in bin, which is an interval of approximately $20 \mathrm{cM}$ between two core markers mapped in the maize genome. The phenotypic variance explained by each QTL ranged from 5.6 to $19.7 \%$, whereas the total phenotypic variance explained by all QTL and their interactions was 76.0\% for Sete Lagoas and 70.4\% for Uberlândia (Table 3). The QTL $q M W S 1.06, q M W S 2.06, q M W S 4.10$, and $q M W S 8.03$ were detected only in Sete Lagoas, whereas $q M W S 2.07, q M W S 3.08$, and $q M W S 4.09$ were observed only in Uberlândia. However, qMWS4.05 and $q M W S 8.05$ were identified in both environments and the resistant parent consistently donated the alleles increasing MWS resistance (Table 3; Fig. 2).

MWS resistance QTL effects were derived from both parents, with gene action ranging from additive to overdominance (Table 3). One dominance-dominance epistatic interaction was found in Uberlândia between QTL $q M W S 2.06$ and $q M W S 3.08$ (Table 3). In general, QTL detected in both locations explained high phenotypic variance in at least one environment, confirming the importance of stable resistance QTL.

Abundance, distribution, and classification of RGA in the maize genome. Of the 112 plant resistance genes used as queries, $71(63.4 \%)$ were found in the maize genome, ranging from 1 copy for Bs2, Gro1.4, Mla12, MLA13, Pi2, Pi-ta, RLM3, RPP27, Tm-2, and Pid2-like to 274 copies for the Serk3A-like genes. We identified 1,697 RGA in all maize chromosomes, varying from 114 RGA on chromosome 9 to 227 on chromosome 1 (Fig. 3). RGA were not randomly distributed along the maize genome but tended to cluster, mainly at the chromosomal ends. A high density of RGA was found on chromosome 10, with 149 predicted genes along $150 \mathrm{Mbp}$ ( $0.99 \mathrm{RGA} / \mathrm{Mbp}$ ), whereas chromosome 9 had the lowest density of RGA (0.71 RGA/Mbp). The 1,697 maize RGA were classified according to known domains: NBS domain was found in 1,439 RGA, LRR in 1,222 RGA, STK in 1,160 RGA, TM in 820 RGA, CC in 168 RGA, and TIR in 3 RGA. Physical position and characterization of maize RGA are available in Supplementary Table S3.

Characterization and expression of RGA colocalized with MWS resistance QTL. Of the 1,697 RGA in the maize genome,
$169(10.0 \%)$ were physically located within the confidence interval of MWS resistance QTL (Table 4), ranging from 1 RGA on $q M W S 4.10$ to 52 RGA on $q M W S 4.05$. Most of the maize RGA that colocalized with MWS resistance QTL belonged to RF01-, Serk3A-, and Pid2-like genes and shared typical NBS $(n=155)$, STK $(n=$ $135), \operatorname{LRR}(n=131), \mathrm{TM}(n=95), \mathrm{CC}(n=12)$, and TIR $(n=1)$ domains.

In all, 41 RGA were selected in silico to lie within the MWS resistance QTL on chromosomes 4 and 8, which had been previously identified (Carson et al. 2005; Moreira et al. 2009). However, only eight of these RGA were successfully converted into STS or CAPS markers. Among those, four RGA were genetically mapped within the confidence interval of the MWS resistance QTL on chromosomes 4 and 8. Those are Pto19 (qMWS4.09), Pto20 (qMWS4.10), Pto99 (qMWS8.03), and Xa26.151.4 (qMWS8.05).

The proteins encoded by Pto19 and Pto20 showed the typical NBS, LRR, and STK domains, corresponding to the predicted maize genes GRMZM2G125308 and GRMZM2G169020, respectively. Pto99 corresponded to GRMZM2G147051, which presented NBS, LRR, STK, TM, and CC domains. The predicted proteins encoded by these three RGA shared 35.2 to $40.3 \%$ sequence identity with the tomato Pto. The RGA Xa26.151.4 (GRMZM2G316907) encoded a predicted protein with NBS, LRR, STK, and TM domains, with $50 \%$ sequence identity with rice $\mathrm{Xa} 26$.

Table 4. Number of resistance gene analogs (RGA) colocalized with maize white spot resistance quantitative trait loci (QTL)

\begin{tabular}{|c|c|c|c|}
\hline \multirow{2}{*}{$\frac{\text { QTL }}{q M W S 1.06}$} & \multicolumn{2}{|c|}{$\begin{array}{c}\text { Flanking markers, physical } \\
\text { position (Mbp) }\end{array}$} & \multirow{2}{*}{$\frac{\text { RGA }}{33}$} \\
\hline & umc1590 (182.875) & bnlg615 (214.461) & \\
\hline$q M W S 2.06$ & umc1004 (176.885) & umc2205 (196.943) & 14 \\
\hline$q M W S 2.07$ & umc1042 (203.075) & $\operatorname{mmc} 0381(218.013)$ & 01 \\
\hline$q M W S 3.08$ & umc1844 (207.033) & bnlg1257 (218.018) & 09 \\
\hline qMWS4.05 & umc1031 (62.130) & dupssr16 (163.296) & 52 \\
\hline qMWS4.09 & umc2287 (232.441) & Pto19 (235.227) & 04 \\
\hline$q M W S 4.10$ & umc1101 (236.714) & Pto20 (236.960) & 01 \\
\hline$q M W S 8.03$ & bnlg669 (22.649) & Pto99 (100.687) & 34 \\
\hline$q M W S 8.05$ & Xa26.151.4 (152.240) & bnlg1823 (167.329) & 21 \\
\hline Total & $\ldots$ & $\ldots$ & 169 \\
\hline
\end{tabular}

Table 3. Maize white spot (MWS) resistance quantitative trait loci (QTL) in tropical maize detected by multiple interval mapping

\begin{tabular}{|c|c|c|c|c|c|c|c|c|}
\hline \multirow[b]{2}{*}{ QTL $^{\mathbf{b}}$} & \multirow[b]{2}{*}{ Marker } & \multirow[b]{2}{*}{ Position (cM) } & \multicolumn{2}{|c|}{ Effect $^{\mathrm{a}}$} & \multirow[b]{2}{*}{$d / a^{c}$} & \multirow[b]{2}{*}{ Type $^{d}$} & \multirow[b]{2}{*}{ LOD $^{\mathbf{e}}$} & \multirow[b]{2}{*}{$R^{2}(\%)$} \\
\hline & & & $\mathbf{a}$ & d & & & & \\
\hline \multicolumn{9}{|l|}{$\overline{\text { Sete Lagoas }}{ }^{\mathrm{f}}$} \\
\hline$q M W S 1.06$ & umc1590 & 146.1 & -0.039 & 0.034 & 0.9 & $\mathrm{D}$ & 3.7 & 8.5 \\
\hline$q M W S 2.06$ & umc1004 & 102.6 & 0.038 & -0.034 & 0.9 & D & 3.2 & 10.6 \\
\hline$q M W S 4.05$ & umc1031 & 26.3 & -0.049 & 0.09 & 0.2 & $\mathbf{A}$ & 6.1 & 13.8 \\
\hline qMWS4.10 & Pto20 & 115.3 & -0.031 & 0.038 & 1.2 & OD & 5.2 & 5.6 \\
\hline$q M W S 8.03$ & Pto99 & 13.8 & -0.039 & -0.001 & 0.0 & A & 4.6 & 12.4 \\
\hline$q M W S 8.05$ & Xa26.151.4 & 71.5 & -0.042 & 0.026 & 0.6 & PD & 4.7 & 14.1 \\
\hline Total & $\ldots$ & $\ldots$ & $\ldots$ & $\ldots$ & $\ldots$ & $\ldots$ & $\ldots$ & 76.0 \\
\hline \multicolumn{9}{|l|}{ Uberlândiag } \\
\hline$q M W S 2.07$ & umc1536 & 122.9 & 0.168 & 0.022 & 0.1 & A & 5.2 & 7.2 \\
\hline$q M W S 3.08$ & umc1844 & 148.1 & 0.185 & -0.101 & 0.5 & PD & 5.1 & 6.4 \\
\hline$q M W S 4.05$ & umc1031 & 14.0 & -0.154 & 0.215 & 1.4 & OD & 2.1 & 6.8 \\
\hline$q M W S 4.09$ & Pto19 & 96.8 & -0.227 & 0.192 & 0.8 & $\mathrm{D}$ & 4.8 & 11.3 \\
\hline$q M W S 8.05$ & Xa26.151.4 & 69.5 & -0.297 & -0.124 & 0.4 & PD & 6.9 & 19.7 \\
\hline$q M W S 2.06 \times q M W S 3.08$ & $\ldots$ & $\ldots$ & $\ldots$ & -0.564 & $\ldots$ & $\mathrm{DD}$ & $\ldots$ & 9.8 \\
\hline Total & $\ldots$ & $\ldots$ & $\ldots$ & $\ldots$ & $\ldots$ & $\ldots$ & $\ldots$ & 70.4 \\
\hline
\end{tabular}

${ }^{a}$ Effects: $\mathrm{a}=$ additive and $\mathrm{d}=$ dominance. Negative signs (-) indicate that the resistant parent allele increases MWS resistance and positive values indicate that the sensitive parent donates the resistance allele.

${ }^{\mathrm{b}}$ QTL in bold were mapped in both locations.

${ }^{c}$ Degree of dominance.

${ }^{\mathrm{d}} \mathrm{A}=$ additive, $\mathrm{PD}=$ partial dominance, $\mathrm{D}=$ dominance, and $\mathrm{OD}=$ overdominance.

e Minimum likelihood of odds.

${ }^{\mathrm{f}}$ Effects based on transformed phenotypic data with signs multiplied by -1 .

${ }^{\mathrm{g}}$ Effects based on nontransformed phenotypic data. 
The expression pattern of RGA Pto19, Pto20, Pto99, and Xa26.151.4, colocalized with MWS resistance QTL on chromosomes 4 and 8, was evaluated in both parental lines at 30 and 60 days after germination under natural occurrence of MWS in the two locations. These candidate genes were preferentially expressed in the resistant line (L31.2.1.2), which donated the QTL alleles increasing resistance, under the environments where the respective QTL were detected (Fig. 4).

\section{Discussion}

This study revealed that approximately $4 \%$ of the predicted maize RGA genes $(1,697)$ shared similar sequences or common structural motifs with 112 known $R$ genes from different plant species. Previously, 861 RGA were found in the maize genome using 73 plant $R$ genes as queries, with less stringent cut-off (e-value $\mathrm{e}^{-8}$ ) than in our analysis (e-value $\mathrm{e}^{-10}$ ) (Liu et al. 2012). The comparatively greater number of RGA found in our study should be due to less $R$ genes used as query by Liu et al. (2012) and improved tools for gene search in the recently reannotated maize genome (Law et al. 2015).

Our whole-genome analysis showed that RGA were clustered, confirming the previous results from maize (Xiao et al. 2007) and other grasses such as rice, sorghum, and brachypodium ( $\mathrm{Li}$ et al. 2010; Monosi et al. 2004). The clustered distribution of $R$ genes may provide a reservoir of genetic variation from which new pathogen specificity can evolve via gene duplication, unequal crossing-over, interlocus recombination, or diversifying selection (Leister et al.
1998). Gene clusters may also be important for activation and expression of the $R$ genes. In tomato, Pto encodes an STK protein kinase, which confers resistance against Pseudomonas syringae (Martin et al. 1993). This gene requires the neighbor Prf gene containing an NBS-LRR domain for its defense activation (Salmeron et al. 1996). In barley, additional genes are required to activate defense mediated by Mla and Mlo R genes in response to Blumeria graminis infection, such as other closely related $\mathrm{R}$ proteins (Ayliffe and Lagudah 2004).

Although the low saturation of the linkage map, the QTL were mapped within intervals smaller than $40 \mathrm{cM}$, and all QTL explained approximately $70 \%$ of the phenotypic variance for the MWS resistance in each Brazilian location, indicating that most of the important regions were covered in the map. This proportion of total phenotypic variance explained by the QTL was considerably higher compared with the previous studies, which ranged from 41.6 to $47.2 \%$ of $R^{2}$ in tropical and temperate maize populations (Carson et al. 2005; Moreira et al. 2009). The detection of dominance effects and dominance-dominance interaction contributed to the high proportion of the phenotypic variance explained by the QTL, because QTL with dominance effects were also reported to play an important role in gray leaf spot resistance in tropical maize (Liu et al. 2016).

Two MWS resistance QTL that were consistently detected in Sete Lagoas and Uberlândia ( $q M W S 4.05$ and $q M W S 8.05$ ) coincided with the ones identified by Carson et al. (2005) ( $q M W S 4.05)$ and Moreira et al. (2009) ( $q M W S 8.05)$. The detection of stable QTL
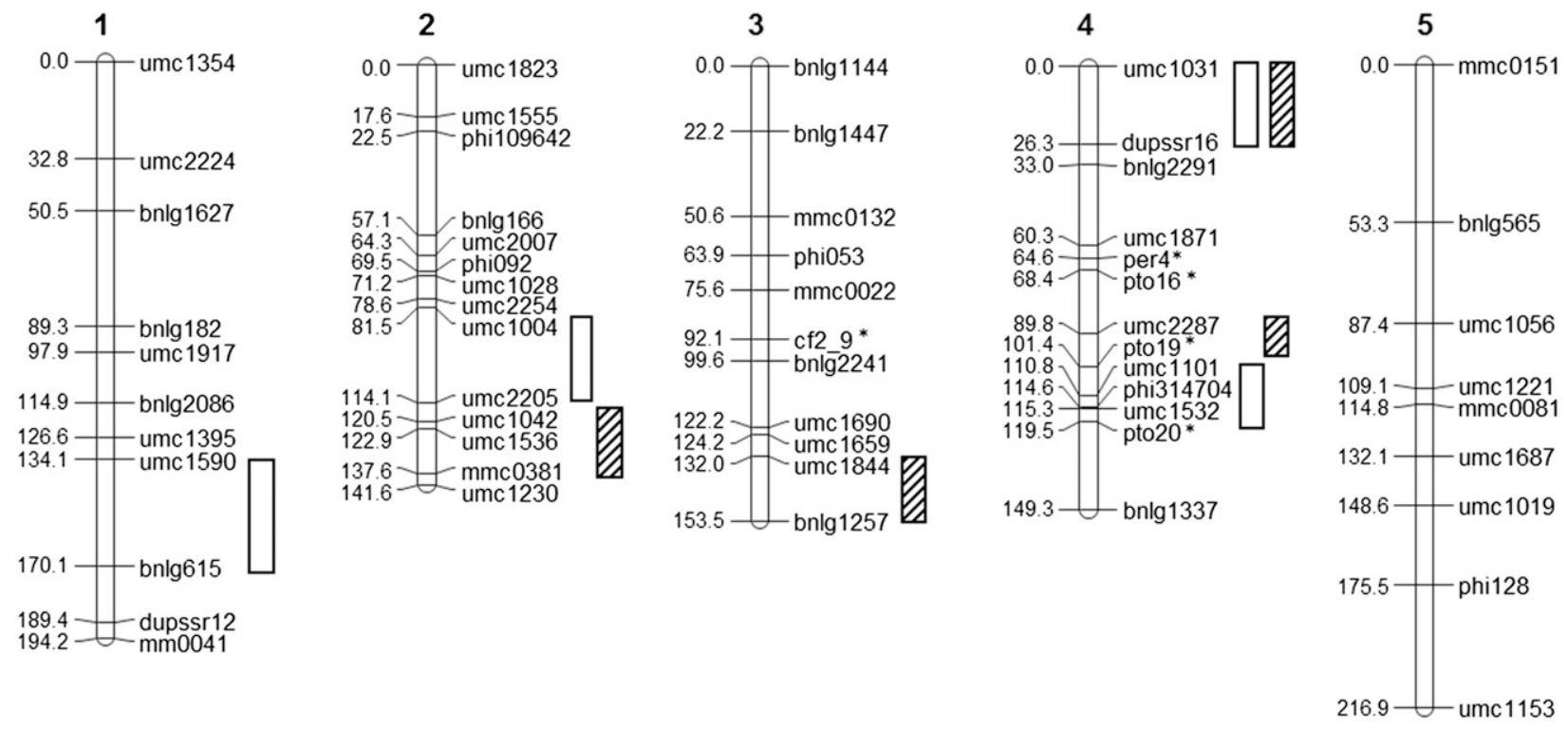

6

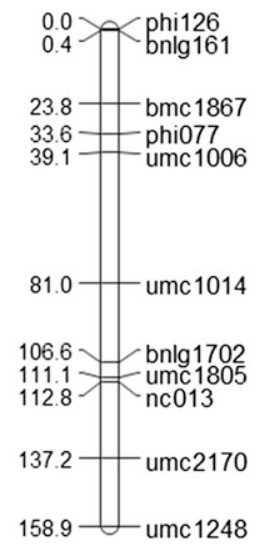

7

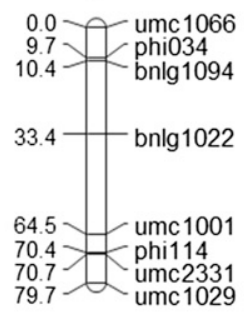

8

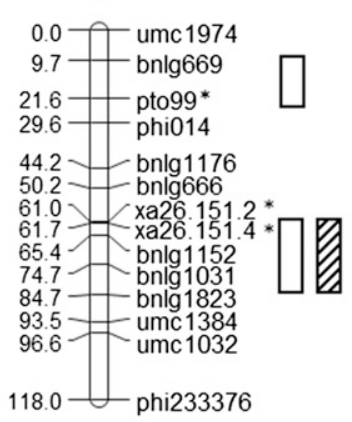

9

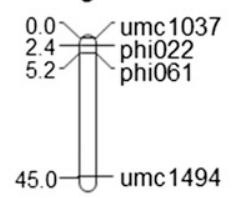

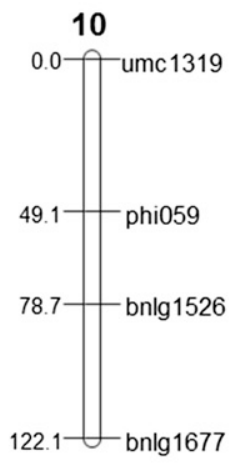

Fig. 2. Maize white spot resistance quantitative trait loci (QTL) detected in Sete Lagoas (white bars) and Uberlândia (stripe bars). QTL (bars) and molecular markers are shown at right side of the chromosomes and the genetic positions in centimorgans are placed at the left side. Markers followed by asterisks are resistance gene analog-tagged markers. 
across the two environments agrees with the high correlation coefficient $(0.80)$ between the responses to MWS in these locations. Thus, $q M W S 4.05$ and $q M W S 8.05$ are good candidates for molecular breeding to introduce a durable resistance to MWS disease in maize cultivars.

The two QTL located on chromosome 2 mapped close to each other but, because their confidence intervals did not overlap, they were considered two environment-specific QTL, which were first reported in our study. The favorable alleles of $q M W S 2.06$, $q M W S 2.07$, and $q M W S 3.08$ derived from the susceptible parental line. The other environment-specific MWS resistance QTL ( $q M W S 1.06, q M W S 4.09, q M W S 4.10$, and $q M W S 8.03$ ) coincided with genomic regions previously associated with resistance to MWS (Carson et al. 2005; Moreira et al. 2009), and their resistance alleles were derived from the resistant parental line. The presence of alleles increasing disease resistance in both parents strongly supports the superiority of some progenies over the resistant parent, suggesting a transgressive segregation of MSW resistance, which was also described by Lopes et al. (2007). Likewise, Liu et al. (2016) confirmed that different susceptible maize lines donated gray leaf spot resistance QTL, suggesting that maize breeding programs should consider the susceptible lines as potential sources of disease resistance genes or QTL.

Many authors mapped RGA within disease resistance QTL intervals (Graham et al. 2000, Wang et al. 2001; Xiao et al. 2007), and used them to develop markers associated with resistance genes in wheat (Chen et al. 2006), barley (Leister et al. 1998), and maize (Wang et al. 2007; Xiao et al. 2006). RGA were also used to isolate disease-resistance genes, such as the maize $R p 1-D$ conferring resistance to rust (Collins et al. 1999).

In our study, four RGA mapped within MWS resistance QTL were characterized for their expression pattern in the parental lines. The

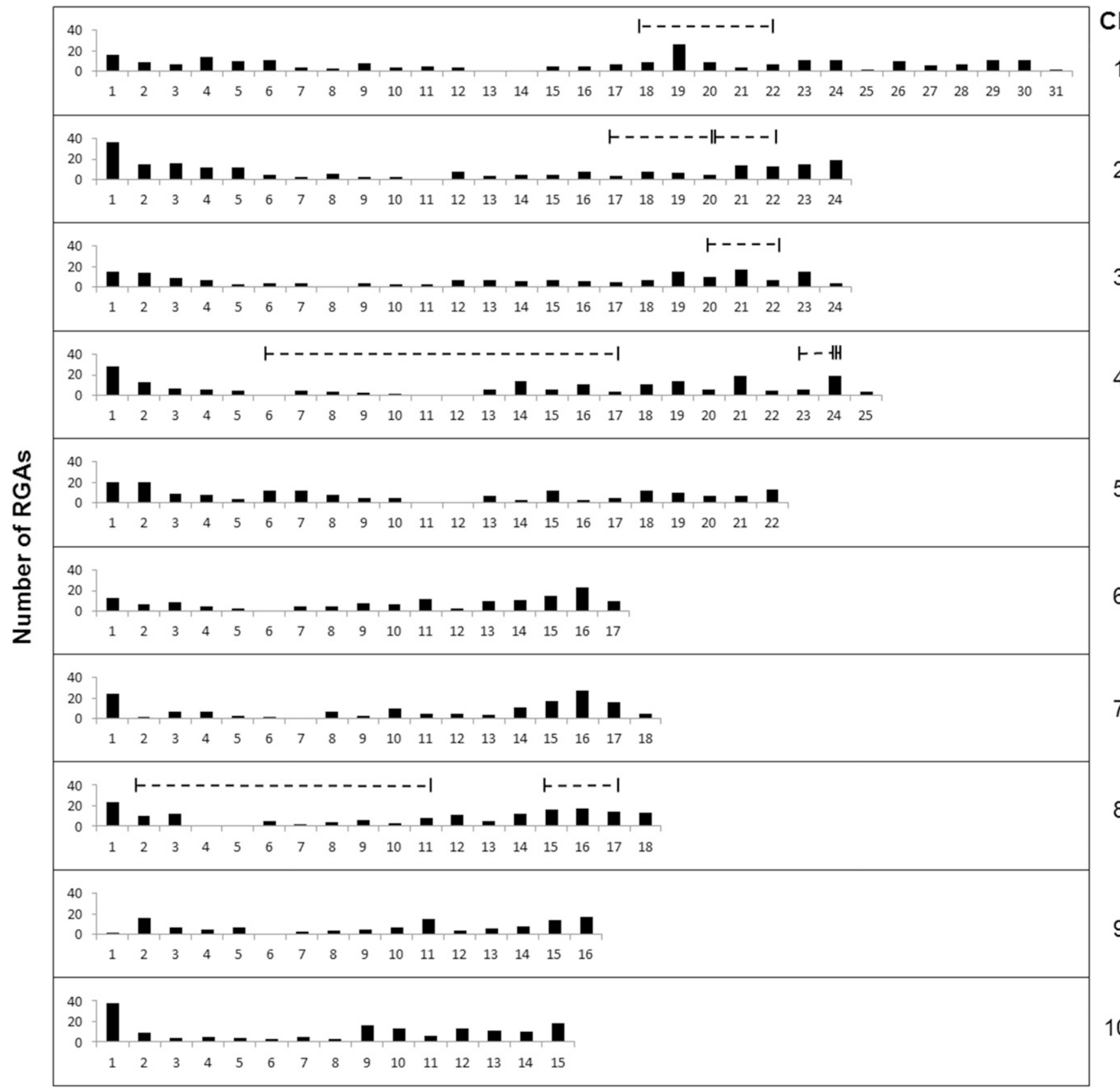

Genome position in Mbp (x 10)

Fig. 3. Distribution of the resistance gene analogs (RGA) in the maize genome. Numbers on the $\mathrm{X}$-axis represent the intervals in Mbp $\times 10$ along each maize chromosome (Chr), which are numbered at the right side of the figure. The $Y$-axis indicates the number of RGA in each chromosome interval. Dotted lines show the estimated positions of the maize white spot resistance quantitative trait loci identified in the present study. 
A

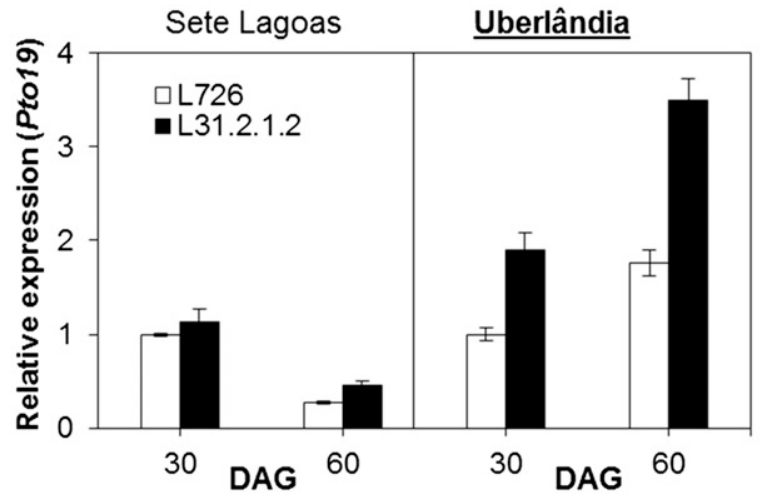

C

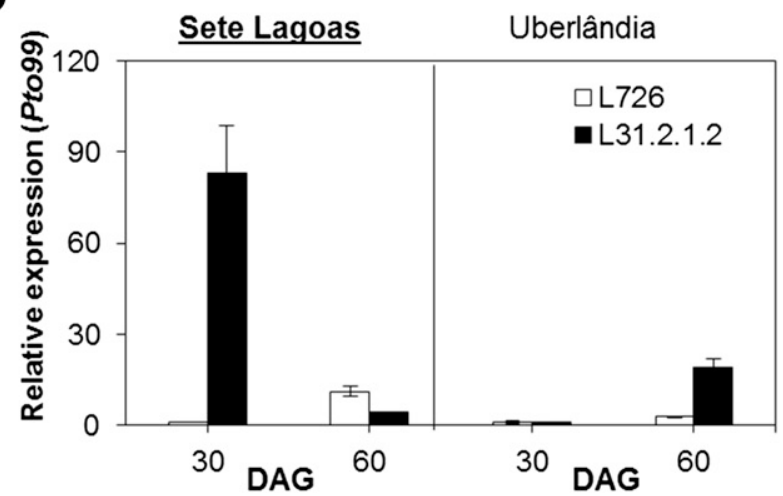

B

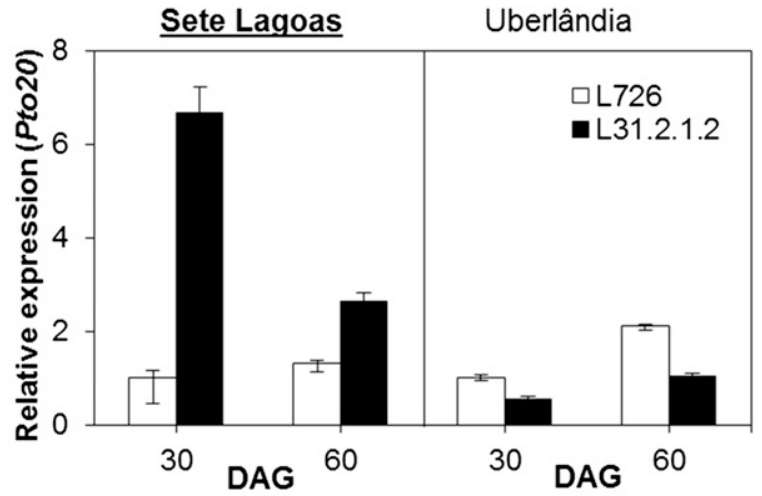

D

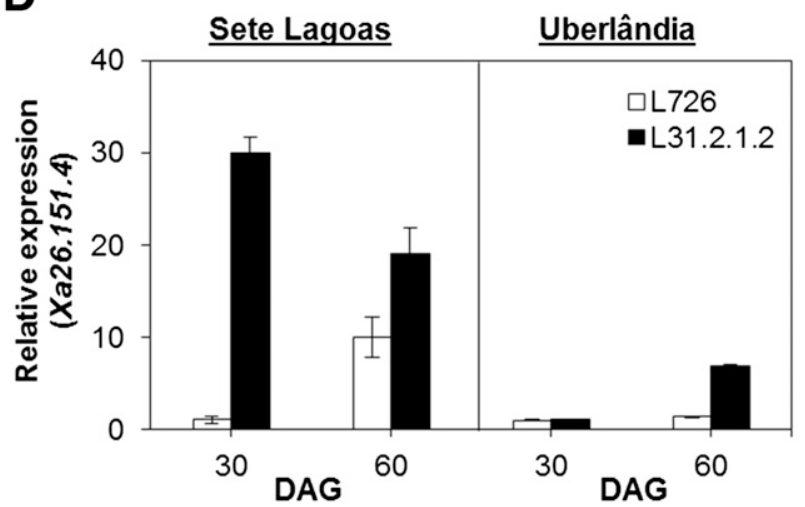

Fig. 4. Relative expression of four resistance gene analogs (RGA) in the resistant (L31.2.1.2) and susceptible (L726) maize lines under field conditions at 30 and 60 days after germination (DAG) in Sete Lagoas and Uberlândia, Brazil. Bars represent the standard error of three technical replicates (five plants per replicate). Sample L726 at 30 days was used as calibrator in each location. Locations where the maize white spot resistance quantitative trait loci colocalized with RGA are underlined and in bold. A, Relative expression of Pto19 underlying the qMWS4.09 detected in Uberlândia. B, Relative expression of Pto20 underlying the qMWS4.10 detected in Sete Lagoas. C, Relative expression of Pto99 underlying the qMWS8.03 detected in Sete Lagoas. D, Relative expression of Xa26.151.4 underlying the qMWS8.05 detected in both locations.

RGA Xa26.151.4, colocalized with $q M W S 8.05$, showed high expression levels in the resistant line, which donated the favorable allele, in both locations. The expression pattern of Xa26.151.4 was highly consistent with the resistance response conferred by the $q M W S 8.05$ under natural occurrence of MWS. In rice, Xa26, also known as Xa3, confers resistance to Xanthomonas oryzae pv. oryzae, which causes bacterial blight, the most devastating plant bacterial disease worldwide (Cao et al. 2007). The expression level of Xa26 was also directly associated with rice resistance against this disease (Cao et al. 2007; Li et al. 2012). In maize, Xa26.151.4 was located at bin 8.05 that harbors QTL associated with resistance to several diseases such as southern leaf blight, gray leaf spot, common rust, common smut, and maize streak virus (Chung et al. 2010). Recently, a wall-associated receptor-like kinase, ZmWAK$R L K 1$, localized in this region was reported as a major gene responsible by resistance against northern corn leaf blight, another important foliar maize disease (Hurni et al. 2015). The candidate Xa26.151.4 does not correspond to gene $Z m W A K$, which was isolated from maize line B37Htn1 and is absent in the B73 reference genome, suggesting that other candidate genes can underlie this MWS resistance QTL.

Two QTL specifically expressed in Sete Lagoas, qMWS4.10 and $q M W S 8.03$, harbored the candidate genes Pto20 and Pto99, respectively, which were highly expressed in the resistant line at 30 days after germination in this location. Pto19 colocalized with qMWS4.09 and was preferentially expressed in the resistant line in Uberlândia at 30 and 60 days, where this QTL was mapped under natural occurrence of MWS. In tomato, the overexpression of Pto in transgenic plants conferred resistance to several bacterial and fungal plant pathogens (Tang et al. 1999). Thus, the expression of all four RGA was highly coincident with the detection of MWS resistance QTL under two field conditions in Brazil.

Interestingly, Pto19, Pto20, Pto99, and Xa26.151.4 share NBS, LRR, and STK domains. The majority of disease resistance genes cloned from 20 plant species encode an NBS attached to LRR domain (Yuan et al. 2015). The NBS domain is responsible for binding and hydrolysis of ATP/GTP (Tameling et al. 2002), modeling the interactions with either the pathogen elicitor or proteins downstream in the signal transduction cascade (Aarts et al. 1998). The LRR regulates predominantly intramolecular interactions, such as protein-protein and ligand-binding (Kobe and Deisenhofer 1994; Matsushima and Miyashita 2012; Padmanabhan et al. 2009), determining the specificity to pathogen elicitors (Hammond-Kosack and Jones 1997; Meyers et al. 1998). STK phosphorylates the hydroxyl group of serine or threonine residues, triggering important steps in disease resistance pathways (Cao et al. 2011).

Our study was performed in a population of moderate size and marker saturation resulting in large QTL regions that encompassed high number of RGA, with a few of them being further evaluated. However, the combination of QTL mapping, in silico RGA prediction, and gene expression analysis strongly revealed stable MWS resistance QTL and RGA potentially useful to improve MWS resistance in breeding programs.

\section{Acknowledgments}

We thank C. R. das Neves and O. A. da Silva for excellent technical assistance at field and laboratory. This work was supported by FAPEMIG, CNPq, and Embrapa.

\section{Literature Cited}

Aarts, M. G. M., Hekkert, B. L., Holub, E. B., Beynon, J. L., Stiekema, W. J., and Pereira, A. 1998. Identification of R-gene homologous DNA fragments genetically linked to disease resistance loci in Arabidopsis thaliana. Mol. Plant-Microbe Interact. 11:251-258.

Alippi, A. M., and López, A. C. 2010. First report of leaf spot disease of maize caused by Pantoea ananatis in Argentina. Plant Dis. 94:487.

Altschul, S. F., Madden, T. L., Schaffer, A. A., Zhang, J., and Zhang, Z. 1997. Gapped BLAST and PSI-BLAST: A new generation of protein database search programs. Nucleic Acids Res. 25:3389-3402.

Ameline-Torregrosa, C., Wang, B. B., O’Bleness, M. S., Deshpande, S., Zhu, H., Roe, B., Young, N. D., and Cannon, S. B. 2008. Identification and characterization of nucleotide-binding site-leucine-rich repeat genes in the model plant Medicago truncatula. Plant Physiol. 146:5-21. 
Ayliffe, M. A., and Lagudah, E. S. 2004. Molecular genetics of disease resistance in cereals. Ann. Bot. (Lond.) 94:765-773.

Belkhadir, Y., Subramaniam, R., and Dangl, J. L. 2004. Plant disease resistance protein signaling: NBS-LRR proteins and their partners. Curr. Opin. Plant Biol. 7:391-399.

Bernardo, R. 2010. Breeding for Quantitative Traits in Plants, 2nd ed. Stemma Press, Woodbury, MN

Bomfeti, C. A., Souza-Pacolla, E. A., Massola-Júnior, N. S., Marriel, I. E., Meirelles, W. F., Casela, C. R., and Paccola-Meirelles, L. D. 2008. Localization of Pantoea ananatis inside lesions of maize white spot diseases using transmission electron microscopy and molecular techniques. Trop. Plant Pathol. 33:63-66.

Box, G. E. P., and Cox, D. R. 1964. An analysis of transformations. J. R. Stat. Soc. [Ser A] 26:211-252.

Cao, A., Xing, L., Wang, X., Yang, X., Wang, W., Sun, Y., Qian, C., Ni, J., Chen, Y., Liu, D., Wang, X., and Chen, P. 2011. A serine/threonine kinase gene Stpk-V, a key member of powdery mildew resistance gene Pm21, confers powdery mildew resistance in wheat. Proc. Natl. Acad. Sci. USA 108:7727-7732

Cao, Y., Ding, X., Cai, M., Zhao, J., Lin, Y., Li, X., Xu, C., and Wang, S. 2007. The expression pattern of a rice disease resistance gene $\mathrm{Xa3} / \mathrm{Xa26}$ is differentially regulated by the genetic backgrounds and developmental stages that influence its function. Genetics 177:523-533.

Carson, M. L. 2001. Inheritance of resistance to Phaeosphaeria leaf spot of maize. Plant Dis. 85:798-800.

Carson, M. L., Stuber, C. W., and Senior, M. L. 2005. Quantitative trait loci conditioning resistance to Phaeosphaeria leaf spot of maize caused by Phaeosphaeria maydis. Plant Dis. 89:571-574.

Chen, J. Y., Huang, J. Q., Li, N. Y., Ma, X. F., Wang, J. L., Liu, C., Liu, Y. F., Liang, Y., Bao, Y. M., and Dai, X. F. 2015. Genome-wide analysis of the gene families of resistance gene analogues in cotton and their response to Verticillium wilt. BMC Plant Biol. 148:1-15.

Chen, Y. P., Wang, H. Z., Cao, A. Z., Wang, C. M., and Chen, P. D. 2006. Cloning of a resistance gene analog from wheat and development of a codominant PCR marker for Pm21. J. Integr. Plant Biol. 48:715-721.

Chung, C. L., Jamann, T., Longfellow, J., and Nelson, R. 2010. Characterization and fine-mapping of a resistance locus for northern leaf blight in maize bin 8.06. Theor. Appl. Genet. 121:205-227.

Collins, N., Drake, J., Ayliffe, M., Sun, Q., Ellis, J., Hulbert, S., and Pryor, T. 1999. Molecular characterization of the maize $R p 1-D$ rust resistance haplotype and its mutants. Plant Cell 11:1365-1376.

Conesa, A., Götz, S., García-Gómez, J. M., Terol, J., Talón, M., and Robles, M. 2005. Blast2GO: A universal tool for annotation, visualization and analysis in functional genomics research. Bioinformatics 21:3674-3676.

Cooley, M. B., Pathirana, S., Wu, H. J., Kachroo, P., and Klessig, D. F. 2000. Members of the Arabidopsis HRT/RPP8 family of resistance genes confer resistance to both viral and oomycete pathogens. Plant Cell 12:663-676.

Fantin, G. M. 1994. Mancha de Phaeosphaeria, doença do milho que vem aumentando sua importância. Biológico 56:39.

Graham, M. A., Marek, L. F., Lohnes, D., Cregan, P., and Shoemaker, R. C. 2000. Expression and genome organization of resistance gene analogs in soybean. Genome 43:86-93.

Gururani, M. A., Venkatesh, J., Upadhyaya, C. P., Nookaraju, A., Pandey, S. K., and Park, S. W. 2012. Plant disease resistance genes: Current status and future directions. Physiol. Mol. Plant Pathol. 78:51-65.

Hammond-Kosack, K. E., and Jones, J. D. G. 1997. Plant disease resistance genes. Annu. Rev. Plant Physiol. Plant Mol. Biol. 48:575-607.

Hurni, S., Scheuermann, D., Krattinger, S. G., Kessel, B., Wicker, T., Herren, G., Fitze, M. N., Breen, J., Presterl, T., Ouzunova, M., and Keller, B. 2015. The maize disease resistance gene $H t n 1$ against northern corn leaf blight encodes a wall-associated receptor-like kinase. Proc. Natl. Acad. Sci. USA 112:8780-8785.

Ingvardsen, C. R., Schejbel, B., and Lübberstedt, T. 2008. Functional markers in resistance breeding. Prog. Bot. 69:61-87.

Jones, J. D. G., and Dangl, J. L. 2006. The plant immune system. Nature 444: 323-329.

Kanazin, V., Marek, L. F., and Shoemaker, R. C. 1996. Resistance gene analogs are conserved and clustered in soybean. Proc. Natl. Acad. Sci. USA 93: 11746-11750.

Kao, C. H., Zeng, Z. B., and Teasdale, R. D. 1999. Multiple interval mapping for quantitative trait loci. Genetics 152:1203-1216.

Khan, A. M., Khan, A. A., Azhar, M. T., Amrao, L., and Cheema, H. M. N. 2016. Comparative analysis of resistance gene analogues encoding NBS-LRR domains in cotton. J. Sci. Food Agric. 96:530-538.

Kobe, B., and Deisenhofer, J. 1994. The leucine-rich repeat: A versatile binding motif. Trends Biochem. Sci. 19:415-421.

Kosambi, D. D. 1943. The estimation of map distances from recombination values. Ann. Eugen. 12:172-175.

Lana, U. G. P., Gomes, E. A., Silva, D. D., Costa, R. V., Cota, L. V., Parreira, D. F., Souza, I. R. P., and Guimarães, C. T. 2012. Detection and molecular diversity of Pantoea ananatis associated with white spot disease in maize, sorghum and crabgrass in Brazil. J. Phytopathol. 160:441-448.

Lander, E. S., and Botstein, D. 1989. Mapping Mendelian factors underlying quantitative traits using RFLP linkage maps. Genetics 121:185-199.
Lander, E. S., Green, P., Abrahamson, J., Barlow, A., Daly, M. J., Lincoln, S. E., and Newburgh, L. 1987. MAPMAKER: An interactive computer package for constructing primary genetic linkage maps of experiment and natural populations. Genomics 1:174-181.

Law, M., Childs, K. L., Campbell, M. S., Stein, J. C., Olson, A. J., Holt, C., Panchy, N., Lei, J., Jiao, D., Andorf, C. M., Lawrence, C. J., Ware, D., Shiu, S. H., Sun, Y., Jiang, N., and Yandell, M. 2015. Automated update, revision, and quality control of the maize genome annotations using MAKER-P improves the B73 RefGen v3 gene models and identifies new genes. Plant Physiol. 167:25-39.

Leister, D., Kurth, J., Laurie, D. A., Yano, M., Sasaki, T., Devos, K., Graner, A., and Schulze-Lefert, P. 1998. Rapid reorganization of resistance gene homologues in cereal genomes. Proc. Natl. Acad. Sci. USA 95:370-375.

Li, H. J., Li, X. H., Xiao, J. H., Wing, R. A., and Wang, S. P. 2012. Ortholog alleles at $\mathrm{Xa3} / \mathrm{Xa} 26$ locus confer conserved race-specific resistance against Xanthomonas oryzae in rice. Mol. Plant 5:281-290.

Li, J., Ding, J., Zhang, W., Zhang, Y., Tang, P., Chen, J. Q., Tian, D., and Yang, S. 2010. Unique evolutionary pattern of numbers of gramineous NBS-LRR genes. Mol. Genet. Genomics 283:427-438.

Liu, H., Lin, Y., Chen, G., Shen, Y., Liu, J., and Zang, S. 2012. Genome-scale identification of resistance gene analogs and the development of their intron length polymorphism markers in maize. Mol. Breed. 29:437-447.

Liu, L., Tan, J., Zhang, Y. D., Li, H. Y., Bi, Y. Q., Shen, Y., Yu, L. J., Jeffers, D. P., Kang, M. S., and Fan, X. M. 2016. QTL mapping for gray leaf spot resistance in a tropical maize population. Plant Dis. 100:304-312.

Livak, K. J., and Schmittgen, T. D. 2001. Analysis of relative gene expression data using real-time quantitative PCR and the $2^{-\Delta \Delta C T}$ method. Methods 25:402-408.

Lopes, M. T. G., Lopes, R., Brunelli, K. R., Silva, H. P., Matiello, R. R., and Camargo, L. E. A. 2007. Controle genético da resistência à mancha-dePhaeosphaeria em milho. Cienc. Rural 37:605-611.

Martin, G. B., Brommonschenkel, S. H., Chunwongse, J., Frary, A., Ganal, M. W. Spivey, R., Wu, T., Earle, E. D., and Tanksley, S. D. 1993. Map-based cloning of a protein kinase gene conferring disease resistance in tomato. Science 262:1432-1436.

Matsushima, N., and Miyashita, H. 2012. Leucine-rich repeat (LRR) domains containing intervening motifs in plants. Biomolecules 2:288-311.

Meyers, B. C., Dickerman, A. W., Michelmore, R. W., Sivaramakrishnan, S., Sobral, B. W., and Young, N. D. 1999. Plant disease resistance genes encode members of an ancient and diverse protein family within the nucleotide binding superfamily. Plant J. 20:317-332.

Meyers, B. C., Shen, K. A., Rohani, P., Gaut, B. S., and Michelmore, R. W. 1998 Receptor-like genes in the major resistance locus of lettuce are subject to divergent selection. Plant Cell 10:1833-1846.

Monosi, B., Wisser, R. J., Pennill, L., and Hulbert, S. H. 2004. Full-genome analysis of resistance gene homologues in rice. Theor. Appl. Genet. 109:1434-1447.

Moreira, J. U. V., Bento, D. A. V., de Souza, A. P., and de Souza, C. L. 2009. QTL mapping for reaction to Phaeosphaeria leaf spot in a tropical maize population. Theor. Appl. Genet. 119:1361-1369.

Ninamango-Cárdenas, F. E., Guimarães, C. T., Martins, P. R., Parentoni, S. N., Carneiro, N. P., and Paiva, E. 2003. Mapping QTLs for aluminum tolerance in maize. Euphytica 130:223-232.

Paccola-Meirelles, L. D., Ferreira, A. S., Meirelles, W. F., Marriel, I. E., and Casela, C. R. 2001. Detection of a bacterium associated with a leaf spot disease of maize in Brazil. J. Phytopathol. 149:275-279.

Padmanabhan, M., Cournoyer, P., and Dinesh-Kumar, S. P. 2009. The leucine-rich repeat domain in plant innate immunity: A wealth of possibilities. Cell. Microbiol. 11:191-198.

Perazzolli, M., Malacarne, G., Baldo, A., Righetti, L., Bailey, A., Fontana, P., Velasco, R., and Malnoy, M. 2014. Characterization of resistance gene analogues (RGAs) in apple (Malus $\times$ domestica Borkh.) and their evolutionary history of the Rosaceae family. PLoS One 9:e83844.

Pérez-y-Terrón, A., Villegas, M. C., Cuellar, A. B. C., Muñoz-Rojas, J., Castañeda-Lucio, M., Hernández-Lucas, I., Bustillos-Cristales, R., BautistaSosa, L., Munive, J. A., Caicedo-Rivas, R., and Fuentes-Ramírez, L. E. 2009 Detection of Pantoea ananatis, causal agent of leaf spot disease of maize in Mexico. Aust. Plant Dis. Not. 4:96-99.

Pinto, N. F. J. A., Fernandes, F. T., and Oliveira, E. 1997. Milho (Zea mays L) Controle de doenças. Pages 821-864 in: Controle de Doenças de Plantas. F. X. R. Vale and L. Zambolim, eds. Editora UFV, Viçosa, MG, Brazil.

Saghai-Maroof, M. A., Soliman, K. A., Jorgensen, R. A., and Allard, R. W. 1984 Ribosomal DNA spacer length polymorphism in barley: Mendelian inheritance, chromosomal location and population dynamics. Proc. Natl. Acad. Sci. USA 81:8014-8018.

Salmeron, J. M., Oldroyd, G. E. D., Rommens, C. M. T., Scofield, S. R., Kim, H. S., Lavelle, D. T., Dahlbeck, D., and Staskawicz, B. J. 1996. Tomato Prf is a member of the leucine-rich-repeat class of plant disease resistance genes and lies embedded within the Pto kinase gene cluster. Cell 86:123-133.

Sanseverino, W., Hermoso, A., D’Alessandro, R., Vlasova, A., Andolfo, G., Frusciante, L., Lowy, E., Roma, G., and Ercolano, M. R. 2013. PRGdb 2.0 Towards a community-based database model for the analysis of R-genes in plants. Nucleic Acids Res. 41:D1167-D1171.

Schuelter, A. R., Souza, I. R. P., Tavares, F. F., Santos, M. X., Oliveira, E., and Guimarães, C. T. 2003. Controle genético da resistência do milho à mancha por Phaeosphaeria. Rev. Bras. Milho Sorgo 2:46-52. 
Sekhwal, M. K., Li, P., Lam, I., Wang, X., and Cloutier, S. 2015. Disease resistance gene analogs (RGAs) in plants. Int. J. Mol. Sci. 16:19248-19290.

Shapiro, S. S., and Wilk, M. B. 1965. An analysis of variance test for normality (complete samples). Biometrika 52:591-611.

Stuber, C. W., Edwards, M. D., and Wendel, J. F. 1987. Molecular-markerfacilitated investigations of quantitative trait loci in maize. II. Factors influencing yield and its component traits. Crop Sci. 27:639-648.

Tameling, W. I. L., Elzinga, S. D. J., Darmin, P. S., Vossen, J. H., Takken, F. L., Haring, M. A., and Cornelissen, B. J. 2002. The tomato $R$ gene products I-2 and Mi-1 are functional ATP binding proteins with ATPase activity. Plant Cell 14:2929-2939.

Tang, X., Xie, M., Kim, Y. J., Zhou, J., Klessig, D. F., and Martin, G. B. 1999. Overexpression of Pto activates defense responses and confers broad resistance. Plant Cell 11:15-29.

Wang, G. X., Chen, Y., Zhao, J. R., Li, L., Korban, S. S., Wang, F. G., Li, J. S., Daí, J. R., and Xu, M. L. 2007. Mapping of defense response gene homologs and their association with resistance loci in maize. J. Integr. Plant Biol. 49:1580-1598.
Wang, S., Basten, C. J., and Zeng, Z.-B. 2012. Windows QTL Cartographer 2.5. N.C. Department of Statistics, North Carolina State University, Raleigh.

Wang, Z., Yamanouchi, U., Katayose, Y., Sasaki, T., and Yano, M. 2001 Expression of the Pib rice-blast-resistance gene family is up-regulated by environmental conditions favoring infection and by chemical signals that trigger secondary plant defenses. Plant Mol. Biol. 47:653-661.

Xiao, W., Zhao, J., Fan, S., Li, L., Dai, J., and Xu, M. 2007. Mapping of genomewide resistance gene analogs (RGAs) in maize (Zea mays L.). Theor. Appl. Genet. 115:501-508.

Xiao, W., Xu, M., Zhao, J., Wang, F., Li, J., and Dai, J. 2006. Genome-wide isolation of resistance gene analogs in maize (Zea mays L.). Theor. Appl. Genet. 113:63-72.

Yuan, Q., Xie, R., Zhang, Z., Ma, Z., Li, J., Li, S., Chen, J., and Lu, Y. 2015. Identification of expressed resistance gene analogs (RGA) and development of RGA-SSR markers in tobacco. Arch. Biol. Sci. 67:467-481.

Zeng, Z. B., Kao, C. H., and Basten, C. 1999. Estimating the genetic architecture of quantitative traits. Genet. Res. 74:279-289. 